\title{
On histological changes of hypothalamus in mice caused by administration of goldthioglucose
}

\author{
By
}

\section{Umon Fukuyama and Ryuichi Watanabe}

Dзpartment of Anatomy, Fukus'ima Medical College, Fukushima

Brecher et Waxle r (1949) and Mayer et $\mathrm{Zighera} \mathrm{(1954)}$ reported the presentation of a remarkable obesity in mice subjected to the injection of $\mathrm{LD}_{53}$ dose of goldthioglucose, but none of these authors have referred to the genesis of this symptom. Likewise, there have been no literatures which elucidate in detail the pharmacological effects of $L D_{\hat{n} \eta}$ of goldthioglucose on individuals as well as its effects on histological changes of visceral organs and tissues.

Throughout the present study, the authors succeeded in realizing that $\mathrm{LD}_{50}$ of goldthioglucose would exert a specific effect on a certain localized portion of the hypothalamus of mice to cause conspicuous histological changes in them. The authors believe that such changes as detected in hypothalamus give a clue to the clarification of the genesis of goldthioglucose obesity. Therefore, this paper will deal with the results obtained from the present study.

\section{Material and Method}

As experimental materials, 85 matured dd mice (weight: 18.0$25.0 \mathrm{~g}$ ) which had been grown with mixed feed were employed.

Powder of goldthioglucose produced by Schering Company in Germany was suspended at the rate of 5 percent in sesame oil, and the mice were intraperitoneally injected with $15 \mathrm{mg}$ each of the suspension. Furnishing sufficient feed, the variation of weight was recorded at intervals of a week.

For the purpose of the histological examination of the brain, the brains of the mice which were assumed to be killed by the toxicity of this agent and those which were slaughtered artificially were immediately taken out and were fixed in $10 \%$ formalin or Bouin's 
fluid. After being embedded in paraffin, frontal serial sections $(8-12 \mu)$ were made from them, and were stained by turns with hematoxylineosin and by $\mathrm{N}$ is s l's method for microscopical examination.

\section{Results}

I. Changes of hypothalamus observed at the early stage after the injection of goldthioglucose.

Of 85 experimental cases ( $\delta 48, \quad \circ 37$ ), those which deceased from toxicity within the period from one through 10 days after the injection of the agent and were slaughtered artificially numbered 54 ( 1830 , o 24 ). The cases selected at random for the purpose of histological examination were 17 ( $\delta 10$, o 7 ).

The changes observable in the hypothalamus of these animals were hemorrhage in different degrees and degeneration and necrosis of the neural tissue. In other words, the process of degeneration and necrosis as well as that of hemorrhage extended towards the rostrocaudal directions from the infundibular region along the ventral side of the medial hypothalamic region. Meanwhile, the parts which were affected most seriously were in the areas ranging from the ventromedial nucleus to the ventral premammillary nucleus and the arcuate nucleus situated on their ventral side, and nerve cells of these nuclei were in the state of degenerative destruction or complete disappearance (Figs. 1 and 2). Besides, the anterior hypothalamic nucleus, the supraoptic nucleus, the dorsomedial nucleus and the dorsal premammillary nucleus were partially or totally affected:according to the degrees of hemorrhage. Throngs in a slight extent of small round cells which appeared like lymphatic cells or microglia cells were observed around the hemorrhagic and necrotic focus. In addition, there was seen a fairly distinct cell infiltration around the perivascular region.

In the other cases which had no hemorrage and merely presented necrotic and destructive findings, it was common that this change was rather distinctly limited and localized in the range including the ventromedial nucleus, the arcuate nucleus and the ventral premammillary nucleus (Fig. 3). In these foci most of the nerve cells of the abovementioned nuclei were in the state of degeneration or disappearance, from which an intensive process of molecular destruction could be assumed. Along this line, the infiltration of various cells was extremely insignificant. 


\section{Changes of hypothalamus of goldthioglucose obese mice.}

Of the 31 surviving mice after the injection of $\mathrm{LD}_{5}$ ) of goldthioglucose, 16 cases ( 10,96 ) were developing obesity (Figs. 4 and 5 show one of the cases). Of these which increased in their weight by $40 \%-$ $107.9 \%$ in the course of 16 weeks, the maximal experimental period, 12 cases which were slaughtered selectively at intervals of a week were subjected to histological examination.

The characteristic feature of the changes observable in the hypothalamus of these mice was that in most of all the cases certain parts or the entire regions of the ventromedial nucleus and the ventral premammillary nucleus were replaced with congregations of large mononuclear cells containing myelin-granules in the cytoplasm and small round cells which seemed to be lymphatic cells or microglia cells. When observed in serial sections, the rostral part of the ventromedial nucleus remained intact. However, with the descent towards the caudal part, the infiltration of these cells came to localize in the ventral part of the ventromedial nucleus and proceeded into the dorsal part gradually to replace this nucleus (Fig. 6). With further descent, the focus exterided to the location of the ventral premammillary nucleus and replaced it. During this process, a part of the arcuate nucleus was also affected. Such a finding may be considered as due to the transformation of the pathological focus of necrosis and destruction into neuroglial cicatrization through the process of organization and repair.

\section{Discussion}

Concerning the obesity observable among patients of hypophysial tumor, Fröhlich (1901) opined the symptom to be due to an endocrine disturbance of the hypophysis (hypopituitarism), while E $\mathrm{rdh}$ e i m (1904) claimed it to be due to a mechanical injury of the overlying hypothalamus caused by the tumor. However, the present study could not obtain any experimental evidences which could support these two theories.

In this respect, the experimental studies on animals by $\mathrm{A} \mathrm{sch} \mathrm{her}$ (1912), Bailey et Bremmer (1921), Cam us et Rouss y (1922), $\mathrm{S} \mathrm{m}$ it h $(1927,30)$ and other workers demonstrated many data which prove the reasonableness of regarding this particular type of obesity as hypothalamic rather than hypophysial. Finally, the experimental studies by Hetherington et Ranson (1939, '40, '42 a, b) and 
Hetherington (1941; '43) which had been made on rats for several years by electrolytic damage of the hypothalamus confirmed the occurrence of "hypothalamic obesity" which is caused independently of the hypophysis. Furthermore, they stated the presence of the most influential localization in the hypothalamus relevant to the occurrence of obesity, and reported in detail that the localization is in a fixed area adjacent to the medial part of the lateral hypothalamic region and includes the ventromedial nuclei, the dorsomedial nuclei and the premammillary nuclei.

Such achievements of these workers should be appreciated very highly in the history of studies on hypothalamic obesity.

In $1943 \mathrm{~B} \mathrm{robeck}$ et al. demonstrated that the obesity of this type is due to the increase of food intake rather than an abnormality of individual metabolism. Moreover, in recent years An and et B robeck (1951 a, b) and Anand et al. (1955) reported that the adjustment of food intake would be regulated by an antagonistic mechanism of the centroneural facilitation and inhibition, and traced the "feeding center" in the lateral hypothalamic region including the lateral hypothalamic nuclei, and on the other hand, the "satiety center" in the medial hypothalamic region including the ventromedial nuclei. And they inferred that the above-mentioned hypothalamic adjustment of food intake would be the most basic reflex function in the neural regulating mechanism.

It may be safely said that the correlationship between the hypothalamus and obesity has been established affirmatively by indubitable evidences although there are many points yet to be studied.

As for the autopsy findings of goldthioglucose obese mice, it is very regrettable that $\mathrm{Brecher}$ et $\mathrm{W}$ a x ler (1949) did not mention any notable changes of the brain.

In the present study, the authors confirmed histologically that the administration of $\mathrm{LD}_{50}$ of goldthioglucose causes hemorrhagic or necrotic destructive changes in the area centering on the medial hyyothalamic region of mice, and that these changes are repaired by cicatrization through the process of organization. It may be an interesting fact that the authors could recognize a distinct cicatrizational tissue in an almost fixed localization including the ventromedial nucleus and the ventral premammillary nucleus, and that this localization is quite similar to the area where $\mathrm{Hethering} t$ on and $\mathrm{R}$ ans on succeeded in causing obesity in rats through electrolytic destruction.

Although the fundamental etiological cause for the destructive 
changes in a fixed localization of the hypothalamus by administration of goldthioglucose has not been made clear, a great significance should be attached to the finding that the goldthioglucose obesity of which the cause has been unknown has been clarified to be a type of hypothalamic obesity.

\section{Conclusion}

Administration of $\mathrm{LD}_{50}$ of goldthioglucose induced peculiar destructive changes of the neural tissue localized in a fixed area of the medial hypothalamic region in the brain of mice.

It is demonstrated that goldthioglucose obesity is a type of the hypothalamic obesity which follows damages of the hypothalamus.

As a further work connected with the present study is being continued by $\mathrm{W}$ at a $\mathrm{nabe}$, one of the authors of this paper, another report in detail will be published in the near future.

\section{References}

1) A n a nd, B.K. and Brobeck, J.R. 1951a. Localization of a "feeding center" in the hypothalamus of the rat. Proc. Soc. Exp. Biol. Med., $77: 323-324$.

2) A n a nd, B.K. and B robeck, J.R. 1951b. Hypothalamic control of food intake in rats and cats. Yale J. Biol. Med., 24: 123-140.

3) A n a nd, B.K., Dua, S. and Shoen berg, K. 1955. Hypothalamic control of food intake in cats and monkeys. J. Physiol., 127 : 143-152.

4) A schner, B. 1912. Über die Funktion der Hypophyse. Pflüg. Arch. f. d. ges. Physiol., 146: 1-146.

5) B a i ley, P. and B remmer, F. 1921. Experimental diabetes insipidus and genital atrophy. Endocrinology, 5: 761-762.

6) B recher, G. and W a x ler, S.H. 1949. Obesity in albino mice due to single injections of goldthioglucose. Proc. Soc. Exp. Biol. Med., 70: 498-501.

7) Brobeck, J.R., Tepperman, J. and Long, C.N.H. 1943. Experimental hypothalamic hyperphagia in the albino rat. Yale J. Biol. Med., 15: 831-853.

8) Camus, J. et Rouss y, G. 1922. Les syndromes hypophysaires; Anatomie et physiologie pathologiques. Rev. neurol., 38: 622-639.

9) E r d h e i m, J. 1904. Über Hypophysenganggeschwülste und Hirncholesteatome. S. B. Akad. Wiss. Wien, 113: 537-726.

10) Frohlich, A. 1901. Ein Fall von Tumor der Hypophysis cerebri ohne Akromegalie. Wien. Klin. Rdsch., i5: 883-886, 906-908. reprinted, 1940. Res. Publ. Ass. Nerv. Ment. Dis., 20: 16-28.

11) Het he ring to n, A.W. and R a n s o n, S.W. 1939. Experimental hypothalamicohypophyseal obesity in the rat. Proc. Soc. Exp. Biol. Med., 41: 465-466.

12) Hetheringto n, A.W. and Ran so n, S.W. 1940. Hypothalamic lesions and adiposity in the rat. Anat. Rec., 78: 149-172.

13) Hetherington, A.W. and Ran son, S.W. 1942a. The relation of various hypothalamic lesions to adiposity in the rat. J. Comp. Neurol., 76: 475-499. 
14) Hetheringt on, A.W. and R an son, S.W. 1942b. Effect of early:hypophysectomy on hypothalamic obesity. Endocrinology, 31: 30-34.

15) Hetherington, A.W. 1941. The relation of various hypothalamic lesions to adiposity and other phenomena in the rat. Am. J. Physiol., i33: 326-327.

16) Hetherington, A.W. 1943. The production of hypothalamic obesity in rats already displaying chronic hypopituitarism. Am. J. Physiol., 140: 89-92.

17) Mayer, J. and $Z$ ighera, C.Y. 1954. The multiple etiology of obesity: Production of two types of obesity in littermate mice. Science, 119: 9697.

18) S mith, P.E. 1927. The disabilities caused by hypophysectomy and their repair: The tuberal (hypothalamic) syndrome in the rat. J. Am. Med. Ass., 88: 158-161.

19) Smith, P.E. 1930. Hypophysectomy and a replacement therapy in the rat. Am. J. Anat., 45: 205-273.

\section{Explanation of plates}

Abbreviations :

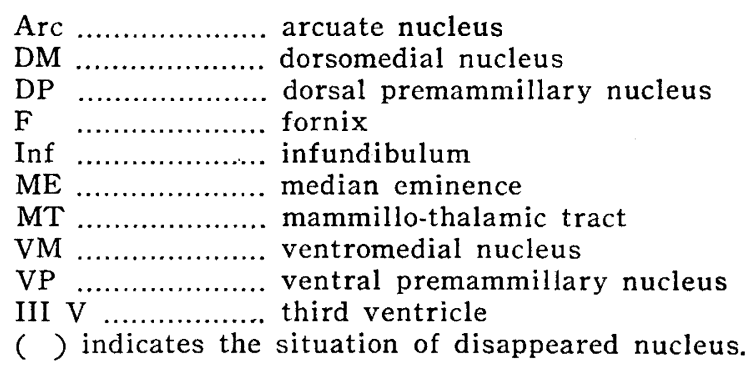

Fig. 1. Remarkable hemorrhage localized in the medial hypothalamic region. Ventromedial nuclei, dorsomedial nuclei, and arcuate nuclei are almost disappeared showing remarkable necrotic damage of the neural tissue. Hemorrhage is also seen in the third ventricle.

( $P$ ) killed on the 6 th day after injection. Fixed in $10 \%$ formalin, hematoxylin and eosin. $\times 40$.

Fig. 2. Hemorrhagic (left) and necrotic (right) changes of the premammillary hypothalamic region. Pathologic focus is evidently localized. Ventral premammillary nuclei are disappearcd, and the dorsal parts of arcuate nuclei are impaired.

( $\delta$ ) killed on the 3rd day after injection. Fixed in Bou in, hematoxylin and eosin. $\times 40$.

Fig. 3. Necrotic focus remarkably localized in the infundibular hypothalamic region. Ventromedial nuclei are disappeared completely, and dorsomedial nuclei and arcuate nuclei show partial changes.

( $P$ ) killed on the 2nd day after injection. Fixed in Bou in, Niss $\mathrm{l} . \times 50$.

Fig. 4. A: Goldthioglucose obese mouse ( $\%$ ). 16th week after injection. $42.0 \mathrm{~g}$ in weight at the slaughtered time (initial weight; $20.3 \mathrm{~g}$ ).

$\mathrm{B}$ : Control mouse undergone no injection. $21.0 \mathrm{~g}$ in weight.

Fig. 5. Dorsal views of the same mice as shown in Fig. 4.

Fig. 6. Infundibular hypothalamic region of a goldthioglucose obese mouse. Ventrom edial nuclei are completely replaced with congregations of cicatrizational cell infiltration (arrow).

(b) killed on the 11 th week after injection. $22.5 \mathrm{~g}$ in initial weight, and $34.2 \mathrm{~g}$ at the slaughtered time. Fixed in $10 \%$ formalin, $\mathrm{N}$ is s $\mathrm{l} . \times 50$. 
Plate I

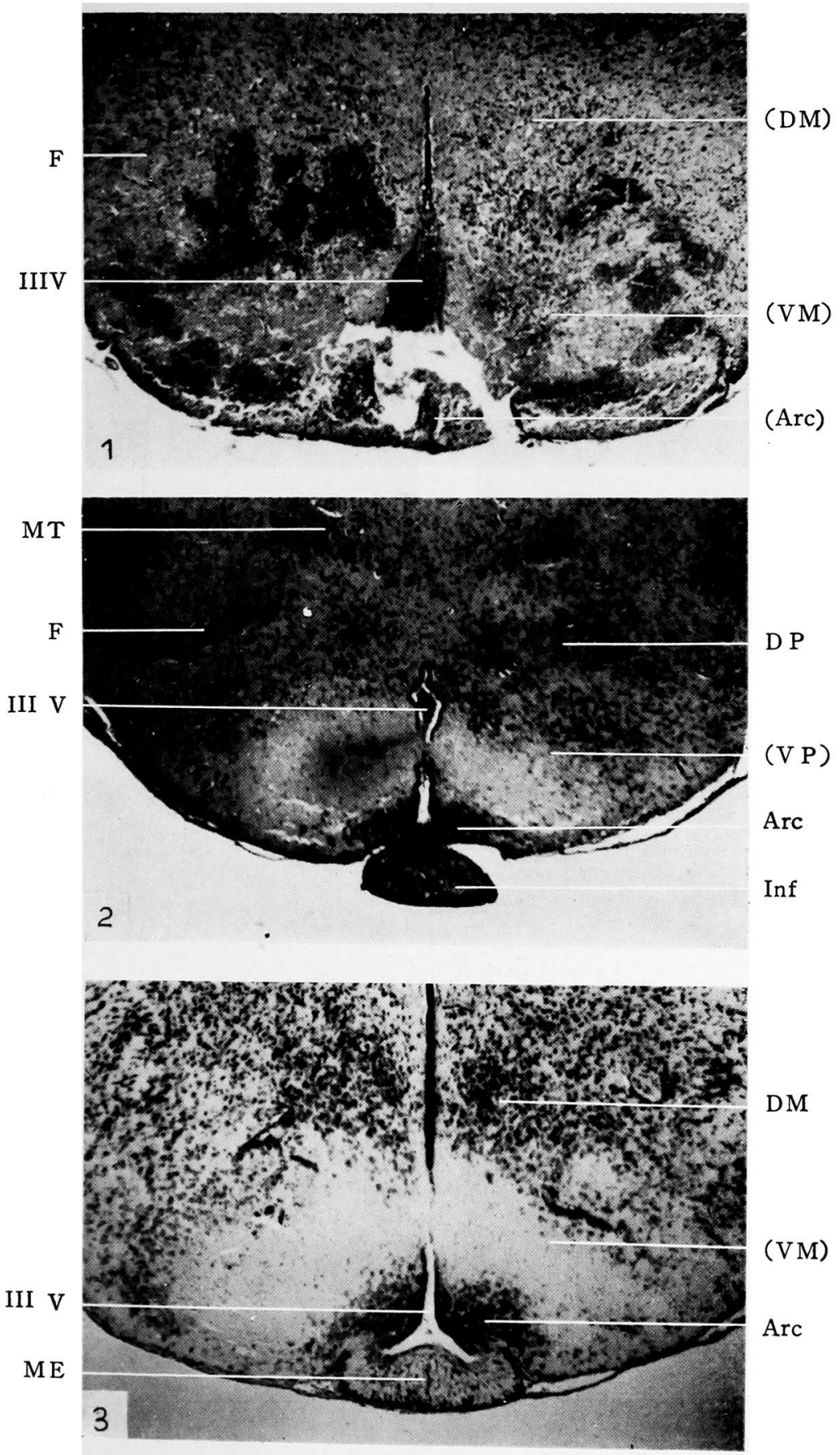

U. Fukuyama and R. Watanabe 

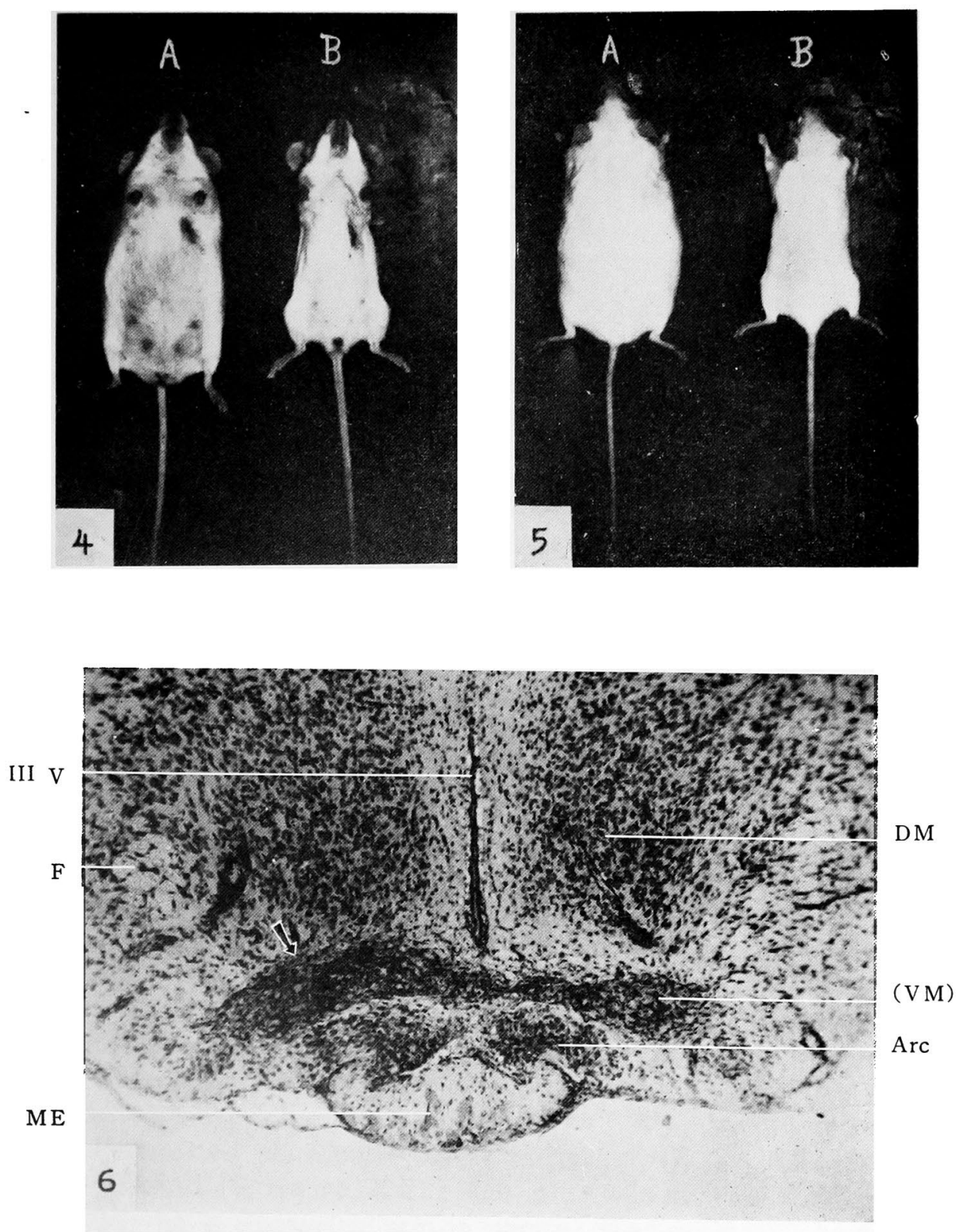

U. Fukuyama and R, Watanabe 